\title{
Validation of the Indonesian Version of the Future Time Perspective (FTP-I) Scale: Study on Student Sample
}

\author{
Gita Irianda Rizkyani Medellu¹, Gumgum Gumelar ${ }^{2}$, Herdiyan Maulana $^{3}$ \\ \{gitairianda@unj.ac.id ${ }^{1}$ \} \\ Faculty of Psychology, State University of Jakarta ${ }^{1,2,3}$
}

\begin{abstract}
There is growing attention in the measurement of future time perspective in the last couple of decades. This concept has been demonstrated to help people manage and achieve goals, including acquiring knowledge, extending social networks, and managing positive emotional experiences. The scale was initially developed in the Occidental countries and widely used there. The authors aimed to translate and validate the Future Time Perspective (FTP) scale into the Indonesian language and test the scale's psychometric properties. Four hundred thirty-one psychology students were recruited to complete the Indonesian version of the scale. Analysis of the scale's internal consistency, construct, and factorial validity was performed using the Exploratory Factor Analysis (EFA). The EFA analysis confirmed the two-factor model of the 10-item FTP-I scale as the best solution. Implications and future recommendations of the current study are discussed.
\end{abstract}

Keywords: Future time perspective, Exploratory factor analysis, Student, Validation

\section{Introduction}

Future time perspective (FTP) is an important concept associated with people's quality of life. FTP defines as individuals' view of personal future, including perceived opportunities and limitations they are expected to encounter in the future [1]. It is characterized by extension and valence [2]; [3]. Extension refers to the period in the future in which an event is represented in someone's perspective. While valence means one's attempt to value future goals as something meaningful, FTP might be considered a personality trait involving people's thoughts, feelings, and actions related to their futures [4]. FTP involves the degree and manner in which the future is integrated into present lives through defining objectives [3]. FTP is an individual disposition to value opportunities, even though they would achieve a distant future [5]. In early studies, Lewin [1] argued that FTP is considered a psychological variable because individuals' life space consists of geographical and social surroundings but also a time dimension. Times provides people to set their activities along with their time range. Time also provides individuals with a point of reference [7]; [8] interprets past, present, and anticipate future experiences. FTP helps people planning their goals and commitments [9]. Therefore, individuals need to acknowledge their own pace in life based on time anticipation that they are perceived.

The characteristic measurement of FTP is the scale of 10 points by Carstensen [10]. He pointed out that FTP could be seen as a unidimensional and simultaneously bipolar idea that can be measured from a 'limited' future (a perception that it takes a short time to live) to a 'open' 
future (an perception that life is ahead of us) [12]. Within the socio-emotional selectivity theory (SST), the FTP scale was developed to ensure a homogenous and one-factorial measurement of the later mental representations in life.

Scholars suggest that the measurement of FTP based on a multidimensional approach is best to describe this concept. Contrary to the previous notion about the range bipolar concept on the future perspective scale, Cate \& John (2007) suggested FTP could be understood by focusing on the opportunities and the limiting factors. Cate \& John (2007) provided evidence for these two-dimensional FTP after doing several studies. Previous studies also provide evidence for this concept's two-dimensional nature [13],[14]. Several non-Western countries have indicated that the FTP scale has two-factor solutions (e.g., the Chinese FTP version by Lyu \& Huang [16]. The multidimensional model also gives the researcher opportunities to explore the FTP concept and other variables, such as age variances.

Most of the studies on FTP scale adaptation were primarily conducted in the occidental nation's context. The oriental country, only Chinese (mainland, Hongkong, \& Taiwan) and Japan, were identified in the literature. This concept has not been systematically developed in Indonesia. Developing an Indonesian version of FTP would potentially assist future research and stakeholders to understand this concept better.

This study aims to develop the Indonesian version of the FTP scale using the translate-back translate approach and investigate its psychometric properties. The analysis would include internal consistency and exploratory factor analysis (EFA). This study was the first in the Indonesian version to develop and validate the FTP.

\section{Methods}

\subsection{Participants}

Participants were 431 (79\% females and $21 \%$ males) psychology students recruited across the country. The online survey was initiated due to social interaction restriction regulation applied during the COVID-19 pandemic. The majority of the respondents (95\%) were lived with their families, and the rest were lived alone (5\%). The three largest groups were those 19 yearsold (25\%), 20 years-old (27\%), and 21 years-old (20\%).

\subsection{Measures}

The online survey consists of an information sheet, consent form, demographic questions, and translated versions of the Future Time Perspective scale were presented to the respondents.

\subsection{Future time perspective Indonesian version scale FTP-I}

The FTP-I scale was developed and administered in the researchers' online form to 431 psychology participants from across the country. The original FTP scale was initially developed by Lang [17]. The scale includes ten items rated on a 7-point Likert scale (from $1=$ very untrue to $7=$ very true). The last three items (Item 8, 9, 10) were coded reversed. Participants' mean scores were used to indicate their FTP level. The internal consistency of this scale was satisfactory (Cronbach's $\alpha=.80$ ). The FTP has been successfully adapted and validated in other languages (e.g., Chinese, Italian, Japanese, \& Turkish) with good psychometric results. 


\subsection{Data collection}

Data have been collected via an online survey. All participants were informed of the confidentiality of the study and requested their consent to take part in this study. The battery consisted of study information and a short report. Participants were encouraged through publications on social media platforms (such as WhatsApp, Facebook, Instagram), public university emails and professional networks of authors by providing a link to an online survey.

\subsection{Study design}

The data were analysed with an Exploratory Factor (EFA) to determine the underlying factor structure of the scale. The analysis of the psychometric properties of the scale with the alpha of Cronbach. Three indicators used for factor retention in the EFA are, 1) Factors had initial eigenvalues > 1.0;2) The changes of point of inflection in the scree plot; and 3) Parallel analysis (PA). Horn's PA would be used to confirm FTP factors' dimensionality by comparing the empirical correlation matrix's eigenvalues to eigenvalues resulted from random correlation matrices [18]. In SPSS version 25, preliminary assumption checks were applied to the data. There was no missing FTP-I data.

\section{Results and Discussion}

\subsection{Result}

\subsubsection{Exploratory factor analysis}

There was no missing FTP-I data. The 10 items in the Indonesian Future Time Perspective Scale (FTP-I) version were reviewed using SPSS version 25 exploratory factor analysis. The best factor structure of the scale was achieved through an iterative method. The main component analysis (PCA) with varimax rotation was carried out resulting in a Keiser-Meyer-Olkin sample factorability adequacy measure $(\alpha=.87)$, with a Bartlett $\mu 2$ test (36) $=1093.9$ and a $p<.001$ confirming that an exploratory model is satisfactory. This EFA analysis produced two factors with their own values compared to Kaisers 1 criterion, which explained 50,59\% of the total variability of the structure. There was no cross-loading of items across other factors. The observation confirmed this two-factor solution on the scree plot graph and Horn's parallel analysis. Horn's parallel analysis was performed in SPSS version 25 using the syntax function written by [19]. As presented in Table 1, this simulation test proved the first two eigenvalues from the actual data (3.74 and 1.31) were higher than those retrieved from the first three bootstrapping data, with eigenvalues of $1.24,1.66$, and 1.11 . 
Table 1. Item and factor loadings of the FTP-I (10 Items)

\begin{tabular}{llcc}
\hline \multicolumn{1}{c}{ No } & \multicolumn{1}{c}{ Item } & \multicolumn{2}{c}{ Factor } \\
\hline Factor 1 & & & 2 \\
ftp1 & Many opportunities await me in the future & .806 & -.076 \\
$\mathrm{ftp} 2$ & I expect that I will set many new goals in the future & .694 & -.028 \\
$\mathrm{ftp} 3$ & My future is filled with possibilities & .670 & -.021 \\
$\mathrm{ftp} 4$ & Most of my life lies ahead of me & .699 & -.262 \\
$\mathrm{ftp} 5$ & My future seems infinite to me & .736 & -.217 \\
$\mathrm{ftp} 6$ & I could do anything I want in the future & .713 & -.076 \\
$\mathrm{ftp7}$ & There is plenty of time left in my life to make new plans & .634 & .077 \\
Factor 2 & & & \\
$\mathrm{ftp} 8$ & I have the sense time is running out. & .263 & .706 \\
$\mathrm{ftp} 9$ & There are only limited possibilities in my future & .392 & .682 \\
$\mathrm{ftp} 10$ & As I get older, I begin to experience time as limited & -.022 & .465 \\
& Eigenvalues & 3.74 & 1.31 \\
\hline
\end{tabular}

\subsection{Discussion}

This current study develops and tests the psychometric properties of the Indonesian version of FTP (FTP-I). The result demonstrated that the FTP-I was a reliable and valid tool. The exploratory factor analysis findings indicated that the FTP-I has a two-factor structure consist of 10 items. This scale was different from the original FTP, which has a one-factor structure. This finding added evidence towards the multidimensional approach suggested by a more recent study of FTP. The FTP-I also has a proper internal consistency.

The primary intention of developing an Indonesian version of the scale was to provide further evidence for its validity and improve the current literature supporting its use. As suggested before, the findings stated two factors loading through measurement and no evidence of a one-factor model. The two eigenvalues from the actual data emphasized the limited and future factors are best to measure the FTP in the Indonesian context. The first factor was defined by items that describe opportunities for future outcomes, and the second factor defined the limited perspective of times. The two factors were remarkably distinct; seven items showed substantial loading on future outcomes factor, and three items were related to limited times perspective. FTP-I leads to focus on present-oriented outcomes with time-limited and openended FTP to more future outcomes. The FTP-I was developed based on the respective sociocultural context. As such, this current scale would potentially capture the construct in a more precise way.

\section{Conclusion}

In summary, this study provides evidence supporting the psychometric properties of the FTP-I scale. The findings support the explanation of the multidimensional approach to be used in Indonesia. The FTP construct's theoretical relevance suggests that a valid multidimensional assessment tool would further explore research and policy development for the years ahead. 
Future studies should consider further post hoc analysis using CFA might strengthen the validation of this tool. This model will explain whether the two factors fit the data rather than the one-factor model. The result would show both factors' independence or suggest the bipolar continuum suggested by Carstensen and Lang FTP scales.

\section{Acknowledgments}

G. Gumelar and H. Maulana contributed equally to this work. We thank all psychology students that participated in the studies. This study was supported by the State University of Jakarta, Faculty of Educational Psychology.

\section{References}

[1] R. A. Cate and O. P. John, "Taking time seriously: A theory of socioemotional selectivity," American Psychologist, vol. 54, no. 3, pp. 165-181, 2007.

[2] T. Gjesme, "Future time orientation and motivation," in In Gjesme, T. \& Nygård, R. (Eds.), Advances in motivation, Oslo, Scandinavian University Press, 1996, pp. 210-222.

[3] J. Husman and W. Lens, "The role of the future in student motivation," Educational Psychologist, vol. 34(2), pp. 113-125, 1999.

[4] D. P. McAdams and B. D. Olson, "Personality Development: Continuity and Change Over the Life Course," Annual Review of Psychology, vol. 61, no. 1, pp. 517-542, 2010.

[5] W. Lens and M. Tsuzuki, "The role of motivation and future time perspective in education and career development," Tiensestraat 102, Belgium, 2005.

[6] K. Lewin, "Field theory and experiment in social psychology: concepts and methods," American Journal of Sociology, vol. 44, no. 6, pp. 868-896, 1939.

[7] S. Mohammed and S. Nadkarni, "Temporal diversity and team performance: The moderating role of team temporal leadership," Academy of management journal, vol. 54, no. 3, pp. 489-508, 2011.

[8] P. M. a. S. M. L. Ringle, "Administrative Leadership: Planning and Time Perspective," The Journal of Higher Education, vol. 54, no. 6, pp. 649-661, 1983.

[9] G. Trommsdorff, "Future Orientation and Socialization," International Journal of Psychology, vol. 18, no. 1-4, pp. 381-406, 1983.

[10] L. Carstensen and F. Lang, "https://lifespan.stanford.edu/projects/future-time-perspective-ftpscale," Standford University, 1996. [Online]. [Accessed 2020].

[11] L. L. Carstensen, D. M. Isaacowitz and S. T. Charles, "Taking time seriously: A theory of socioemotional selectivity," American Psychologist, vol. 54, no. 3, pp. 165-181, 1999.

[12] G. Coudin and L. M. Liam, "Being well as time goes by: Future time perspective and weil-being," International Journal of Psychology and Psychological Therapy, vol. 11, no. 2, pp. 219-232, 2011.

[13] J. N. d. B. W. B. P. A. M. L. P. P. N. a. D. R. Stough, "Hour glass half full or half empty? Future time perspective and preoccupation with negative events across the life span," Psychology and Aging, vol. 31, no. 6, pp. 558-573, 2016.

[14] H. a. F. M. Zacher, "Remaining Time and Opportunities at Work: Relationships Between Age, Work Characteristics, and Occupational Future Time Perspective," Psychology and Aging, vol. 24, no. 2, pp. 487-493, 2009.

[15] H. Lyu and X. Huang, "Development and validation of Future Time Perspective Scale for Adolescents and Young Adults," Time \& Society, vol. 25, no. 3, pp. 533-551, 2016.

[16] A. Brothers, H. Chui and M. Diehl, "Measuring future time perspective across adulthood: Development and evaluation of a brief multidimensional questionnaire," Gerontologist, vol. 54, no. 6, pp. 1075-1088, 2014. 
[17] F. R. Lang and L. L. Carstensen, "Time counts: future time perspective, goals, and social relationship," Psychology and Aging, vol. 17, no. 1, pp. 125-139, 202.

[18] U. Lorenza-Seva, "How to report the percentage of explained common variance in exploratory factor analysis," Universitat Rovira i Virgili, Tarragona, 2013.

[19] B. P. O'Connor, "). SPSS and SAS programs for determining the number of components using parallel analysis and Velicer's MAP test," Behavior Research Methods, Instruments, and Computers, vol. 32, no. 3, pp. 396-402, 2000.

[20] J. E. Nurmi, "How do adolescents see their future? A review of the development of future orientation and planning," Developmental Review, vol. 11(1), pp. 1-59, 1991.

[21] R. Seginer, "Adolescent future orientation," 12 2019. [Online]. Available: https://scholarworks.gvsu.edu/cgi/viewcontent.cgi?article=1056\&context=orpc. [Accessed 06 2020]. 